С. В. Калашников, Е. С. Шолохов, Н. А. Романов, А. В. Номоев. Установка для исследования свойств жидких кристаллов в электрическом и слабом магнитном полях

УДК 53.072 .13

DOI 10.18101/2306-2363-2020-1-23-28

\title{
УСТАНОВКА ДЛЯ ИССЛЕДОВАНИЯ СВОЙСТВ ЖИДКИХ КРИСТАЛЛОВ В ЭЛЕКТРИЧЕСКОМ И СЛАБОМ МАГНИТНОМ ПОЛЯХ
}

(C) Калашников С. В.

директор Центра коллективного пользования, Бурятский государственный университет имени Доржи Банзарова Россия, 670000, г. Улан-Удэ, ул. Смолина, 24а

E-mail: Betch_Kail@mail.ru

(C) Шолохов Е. С.

научный сотрудник,

Лаборатория физики композитных материалов

Институт физического материаловедения СО РАН

Россия, 670047, г. Улан-Удэ, ул. Сахьяновой, 6

y-mail: EShol@ya.ru

(C) Романов Н. А.

научный сотрудник,

Лаборатория физики композитных материалов

Институт физического материаловедения СО РАН

Россия, 670047, г. Улан-Удэ, ул. Сахьяновой, 6

E-mail: NRomanovv@mail.ru

\section{(C) Номоев А. В.}

доктор физико-математических наук,

заведующий Лабораторией физики композитных материалов,

Институт физического материаловедения СО РАН

Россия, 670047, г. Улан-Удэ, ул. Сахьяновой, 6

E-mail: nomoevav@mail.ru

Рассмотрена конструкция экспериментальной установки для измерения электрооптических свойств жидкокристаллических пленок в динамически изменяющихся электрическом или магнитном поле. В отличие от применяемых обычно разовых импульсных магнитных полей с высокой индукцией, в рассматриваемой установке магнитное поле генерируется с относительно высокой частотой. Представлено краткое описание конструкции и принципов работы установки. Предлагаемое техническое решение позволяет эффективно исследовать различные параметры жидких кристаллов и полимерных пленок на их основе. Система создания магнитного поля позволяет работать с такой же частотой, с какой производится исследование жидких кристаллов с помощью управления электрическим полем.

Ключевые слова: экспериментальная установка; жидкие кристаллы; управление магнитным полем; импульсные поля; жидкокристаллические пленки; индукция; диэлектрическая проницаемость.

Для цитирования: Калашников С. В., Шолохов Е. С., Романов Н. А., Номоев А. В. Установка для исследования свойств жидких кристаллов в электрическом и слабом магнитном полях // Вестник Бурятского государственного университета. Химия. Физика. 2020. Вып. 1. С. 23-28. 
Жидкие кристаллы имеют широкое научное и прикладное значение. Достаточно энергетически слабое внешнее воздействие, например, в виде электрического поля, вызывает изменение оптических свойств жидких кристаллов. Анизотропия их различных свойств - наиболее ценный аспект данного материала. Благодаря ей жидкие кристаллы нашли применение в научных исследованиях, в приборах отображения информации, в радиотехнике в волновых трактах и пр. [1].

В наше время создано большое число разновидностей жидких кристаллов, в том числе и восприимчивых к магнитному полю. Как правило, магнитным полем или задается начальная ориентация молекул жидких кристаллов [2], или производится динамическое управление их ориентацией. Как правило, при этом используются редкоземельные магниты для начальной ориентации жидких кристаллов, а в случае управления ориентацией молекул - импульсные магнитные поля с высокой индукцией (от $\sim 1$ Тл). Но в некоторых случаях, в практике исследований свойств жидкокристаллических полимерных пленок, модифицированных композитными или ферромагнитными наночастицами, требуется определение их оптико-временных свойств в сравнительно слабых $(\sim 0,1$ Тл) магнитных полях, но следующих в виде импульсов при частотах, соизмеримых с максимальными частотами отклика молекул жидких кристаллов (50-500 Гц). Иногда требуется исследование жидкокристаллических пленок при воздействии одновременно и электрического, и магнитного полей [3-4]. Данным условиям отвечает созданная экспериментальная установка, описание которой приведено ниже.

\section{Общее описание установки}

В рассматриваемой установке для исследования оптико-временных свойств жидких кристаллов, воздействие на них может производиться как электрическим, так и магнитным полем.

Электрическое напряжение или сила тока, необходимые для оптического открытия ячейки жидких кристаллов обоими методами, регулируется в широких пределах, что позволяет исследовать зависимость их электрооптических свойств от напряженности (или индукции) прикладываемых полей.

Установка обладает высокой эффективностью в плане измерения быстродействия и световой прозрачности ячейки жидких кристаллов, так как возможно управлять в широких пределах и частотой электрического сигнала, подаваемого на ячейку. Кроме того, кривые импульса напряжения и кривая, характеризующая световую прозрачность жидких кристаллов, отображаются на одном экране двухканального осциллографа одновременно, что повышает точность измерений, позволяет выявить другие динамические характеристики работы ячейки.

Экспериментальная установка работает следующим образом: жидкие кристаллы в виде капсул в полимере расположены в ячейке, представляющей собой две плоскопараллельных пластины с напылёнными на них оптически прозрачными токопроводящими покрытиями, к которым прикладывается импульсное напряжение от электрической системы, описанной ниже. Магнитное поле к ячейке прикладывается за счет соленоида, расположенного на образцедержателе.

Лазерный пучок освещает образец перпендикулярно к его поверхности. Интенсивность прошедшего чрез ячейку света измеряется с помощью фотодатчика. Сигнал с него подается на один из каналов осциллографа. Система управления 
С. В. Калашников, Е. С. Шолохов, Н. А. Романов, А. В. Номоев. Установка для исследования свойств жидких кристаллов в электрическом и слабом магнитном полях

жидкими кристаллами состоит из генератора прямоугольных импульсов и коммутатора, задающего амплитуду этих импульсов (от 0 до 300 В) к обкладкам стекол ячейки жидких кристаллов, или задающего силу тока в обмотке соленоида образцедержателя, в зависимости от выбранного режима. Напряженность электрического поля и индукция магнитного поля задаются перпендикулярно поверхности стекол. Внешний вид ячейки с пленкой жидких кристаллов показан на рис. 1.

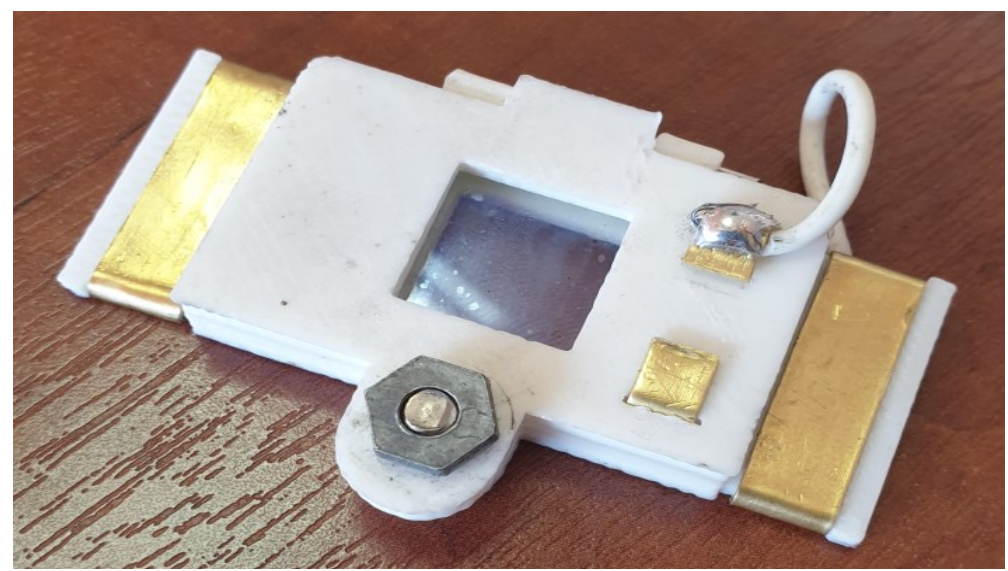

Рис. 1. Внешний вид ячейки жидких кристаллов в кассете образцедержателя

Регистрируя подачу импульсного напряжения на ячейку и сигнал с фототранзистора, можно судить о времени задержки открытия и закрытия жидких кристаллов. По величине сигнала с фотодатчика можно определить прозрачность ЖК в открытом и закрытом состояниях.

Структурная схема установки приведена на рис. 2. Установка может также включать модули определения диэлектрической проницаемости двумя методами, методики работы которых рассмотрены в [5].

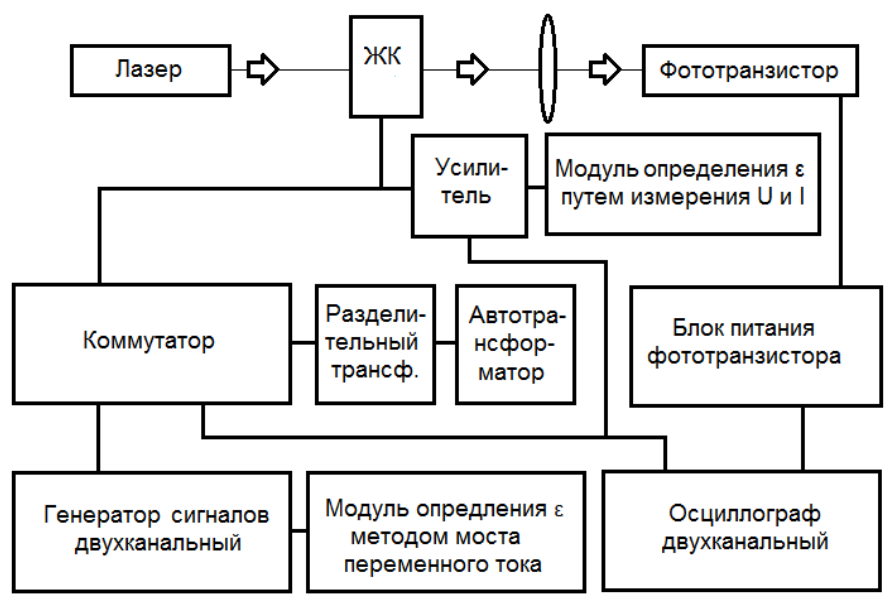

Рис. 2. Структурная схема экспериментальной установки для измерения электрооптических характеристик жидких кристаллов 


\section{Электрическая схема экспериментальной установки}

Электрическая система состоит из нескольких модулей: модуля питания фотодатчика, коммутатора сигналов на жидкокристаллическую ячейку, собственно ячейка, ее кассета и образцедержатель, генератор электрических сигналов, двухканальный осциллограф, автотрансформатор, разделительный трансформатор.

На рис. 3 представлена принципиальная электрическая схема установки.

Модуль А1 представляет собой блок питания, выдающий постоянное стабилизированное напряжение 24 В. Он включает в себя индикатор сети EL0, понижающий трансформатор TV1, выпрямительный мост VD0, конденсатор фильтрующий C1, интегральный стабилизатор DA1, балластный конденсатор C2. Далее напряжение блока A1 коммутируется фототранзистором VT1 в зависимости от его освещенности лазером и подается на первый канал осциллографа.

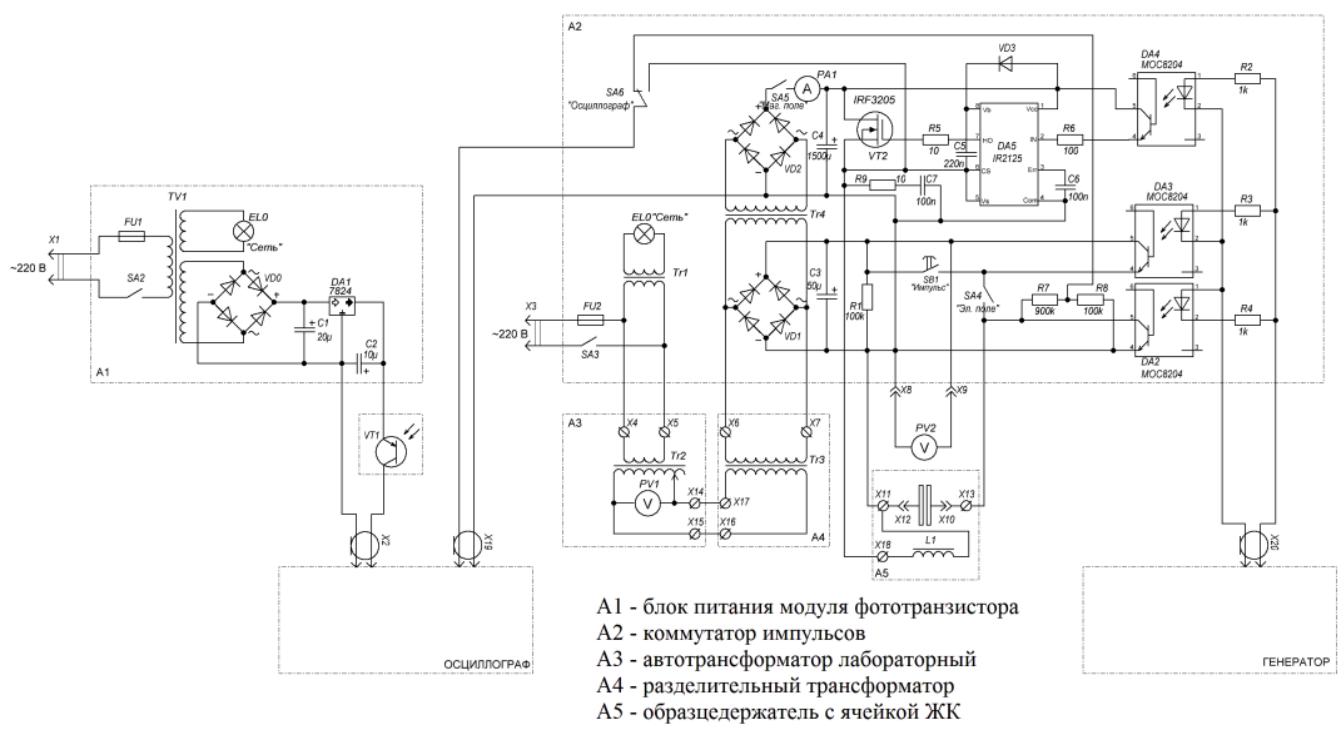

Рис. 3. Принципиальная схема электрических систем экспериментальной установки

Модуль А2 представляет коммутатор, подающий регулируемое постоянное напряжение на обкладки ЖК ячейки или на соленоид синхронно импульсам генератора сигналов. Он работает следующим образом. Ток из сети подается через выключатель SA3 и плавкий предохранитель FU2 на вход регулируемого автотрансформатора $\operatorname{Tr} 2$, после чего в разделительный трансформатор, служащий для гальванической развязки цепей установки от сети, затем в модуле А2 он выпрямляется диодным мостом VD1, фильтруется конденсатором С3 и при открытом оптотранзисторе DA3 и включенном выключателе SA4 «Электрическое поле» подается на образцедержатель к обкладкам жидкокристаллической ячейки, и одновременно через делитель напряжения R7-R8, переключатель SA6 на второй канал осциллографа. Делитель уменьшает напряжение на входе в осциллограф в 10 раз. Оптотранзистор DA2 открывается при закрытии оптотранзистора DA3 и служит для того, чтобы при снятии сигнала остаточный заряд с ячейки стекал 
С. В. Калашников, Е. С. Шолохов, Н. А. Романов, А. В. Номоев. Установка для исследования свойств жидких кристаллов в электрическом и слабом магнитном полях

через него, чем обеспечивается крутость фронта закрытия ячейки жидких кристаллов. Оптотранзисторы управляются от генератора прямоугольных импульсов через токоограничивающие резисторы $R 3$ и $R 4$. Включение фотодиодов встречно-параллельное, чем обеспечивается их последовательная работа синхронно полупериодам прямоугольных сигналов с генератора.

Для контроля напряжения, подаваемого на ячейку, к модулю подключен вольтметр PV2. Для ручной подачи напряжения к жидкокристаллической ячейки при тестировании установлен кнопочный включатель SB1.

Напряжение с разделительного трансформатора так же подается на трансформатор Tr4, служащего для питания соленоида L1 образцедержателя пониженным напряжением (номинальное - 12 В). На соленоид ток подается так же синхронно верхним полуволнам импульсов от генератора, что обеспечивается коммутацией тока силовым полевым транзистором VT2 (включенным в виде верхнего ключа), импульс на затвор которого подается от драйвера верхних ключей DA5, который, в свою очередь, управляется оптотранзистором DA4, открывающимся от сигналов генератора импульсов.

Соленоид представляет собой катушку из 50 витков медного провода на каркасе и размещен на образцедержателе так, что в его центре (в области однородного магнитного поля) находится жидкокристаллическая ячейка. Так как при резкой коммутации тока в соленоиде, обладающим заметной индуктивностью, образовываются всплески ЭДС самоиндукции, для их гашения установлен RCфильтр, включающий конденсатор С7 и резистор R9.

Включение режима работы с соленоидом производится выключателем SA5 «Магнитное поле». При этом импульсы с соленоида могут быть так же поданы на второй вход осциллографа посредством переключателя SA6. Средний ток в цепи соленоида можно контролировать с помощью амперметра PA1, а изменять - вращением ручки автотрансформатора $\operatorname{Tr} 2$.

В системе используется осциллограф модели TDS 1021 и генератор импульсов Ригол DG 4162.

\section{Заключение}

Предлагаемое техническое решение позволяет эффективно исследовать различные параметры жидких кристаллов и полимерных пленок на их основе, в том числе динамично изменяющиеся. Система создания магнитного поля позволяет работать с такой же частотой, с какой производится исследование жидких кристаллов с помощью управления электрическим полем [6].

Работа выполнена при поддержке гранта РФФИ №18-42-030004.

\section{Литература}

1. Беляев Б. А., Лексиков А. А., Сержантов А. М., Шабанов В. Ф. Физические основы создания электрически управляемых микрополосковых устройств // Известия вузов. Физика. 2008. Т. 51, № 9. С. 36-45.

2. Жаркова Г. М., Фомичев В. П. Светопропускание полимерно-дисперсных жидких кристаллов, сформированных в слабых магнитных полях // Сибирский физический журнал. 2018. Т. 13, № 3. С. 47-54. 
3. Захаров А. В. Динамика деформации нематика под действием сильных скрещенных электрического и магнитного полей // Физика твердого тела. 2018. Т. 60, № 3. C. $603-608$.

4. Геворкян Э. В., Хотькин С. О. К методике изучения поведения жидких кристаллов в переменных электромагнитных полях // Вестник Московского государственного областного университета. Серия: Физика-Математика. 2019. № 4. С. 51-59.

5. Kalashnikov S. V., Romanov N. A., Nomoev A. V. Study of the properties of liquid crystals modified by nanoparticles // J. Applied Physics. 2016. V. 119(9). P. 094304.

6. Романов Н. А., Номоев А. В., Калашников С. В. Установка для измерения электрооптических свойств жидких кристаллов // Вестник Бурятского государственного университета. Химия. Физика. 2015. Вып. 3. С. 114-119.

\section{EXPERIMENTAL SYSTEM FOR STUDYING THE PROPERTIES OF LIQUID CRYSTALS IN AN ELECTRIC AND WEAK MAGNETIC FIELD}

Kalashnikov S. $V$.

Director of Core Facilities

Buryat State University

670000, Ulan-Ude, Smolina, Str., 24a

Sholokhov E. S.

Research

Laboratory of Physics of Composite Materials

Institute of Physical Materials Science SB RAS

670047, Ulan-Ude, Sakhyanovoy, Str., 6

E-mail:nomoevav@mail.ru

Romanov N. A.

Researcher

Laboratory of Physics of Composite Materials

Institute of Physical Materials Science SB RAS

670047, Ulan-Ude, Sakhyanovoy, Str., 6

E-mail: nomoevav@mail.ru

Nomoev A. $V$.

Doctor of Physical and Mathematical Sciences

Head of Laboratory of Physics of Composite Materials

Institute of Physical Materials Science SB RAS

670047, Ulan-Ude, Sakhyanovoy, Str., 6

E-mail: nomoevav@mail.ru

The design of an experimental installation to measure electro-optical properties of liquid crystal films in a dynamically changing electric or magnetic field is considered. In contrast to the usually used single-time pulsed magnetic fields with high induction, the magnetic field is generated with a relatively high frequency in the installation under consideration. A brief description of the design and operating principles of the installation is provided. The proposed technical solution allows us to effectively study various parameters of liquid crystals and polymer films based on them. The system for creating a magnetic field allows you to work with the same frequency as the study of liquid crystals using electric field control goes on.

Keywords: experimental setup; liquid crystals; magnetic field control; pulse fields; liquid crystal films; induction; permittivity. 